\title{
STRUCTURAL AND ARCHITECTURAL CHARACTERISATION OF OLD BUILDINGS STOCKS: CASE STUDY OF THE OLD CITY CENTRE OF SEIXAL, PORTUGAL, REBUILT AFTER THE GREAT 1755 LISBON EARTHQUAKE
}

\author{
Tiago Miguel FERREIRA ${ }^{\mathrm{a}}$, Cátia SANTOS ${ }^{\mathrm{b}}$, Romeu VICENTE ${ }^{\mathrm{a}}$, J. A. R. MENDES DA SILVA ${ }^{\mathrm{b}}$ \\ ${ }^{a}$ RISCO, Department of Civil Engineering, University of Aveiro, Campus Universitário de Santiago, \\ 3810-193 Aveiro, Portugal \\ ${ }^{b}$ LAETA, Department of Civil Engineering, University of Coimbra, Rua Luís Reis Santos, \\ Pólo II da Universidade, 3030-788 Coimbra, Portugal
}

Received 28 May 2015; accepted 02 November 2015

\begin{abstract}
This paper addresses the issue of historical urban centres from the perspective of the analysis and inventory of building features. The cataloguing process of the building typologies is presented herein as a synthesis of the main construction forms, using as a case study the old city centre of Seixal, Portugal, rebuilt in its present form after the great 1755 Lisbon earthquake. As marks of an historical and architectural heritage, old urban centres should be protected, safeguarded and potentialised. Therefore, it is essential to have a complete understanding of the diachronic process of both buildings and urban mesh, in order to support qualified, conscientious and sustainable interventions.
\end{abstract}

Keywords: historical building centres, built heritage, building typologies, constructive characterization, rehabilitation.

\section{Introduction}

Throughout time, cities are exposed to numerous events, with different origins and impacts, which go changing their image and characteristics. In consequence of the 1755 Lisbon earthquake, several cities were affected, and a large amount of built heritage was irretrievably lost. The city of Seixal, located about 25 $\mathrm{km}$ south of Lisbon, was one of the most affected ones, going through a long and deep reconstruction process, which represented a main role in the current image of the city.

Thus, this paper aims at presenting an up-to-date overview of the built heritage in the old city centre of Seixal, particularly concerning materials and processes used in their reconstruction after the 1755 Lisbon earthquake. The research work is based on a detailed survey campaign wherein 99 out of 380 old masonry buildings, focusing on three different domains: (i) architectural typologies and drawings; (ii) structural and non-structural building features and defects and (iii) socio-demographic characterisation, which will be individually discussed throughout this paper (further results in these domains can be seen in Ferreira et al. (2013) and Santos et al. (2013)).

\section{Inspection and buildings appraisal}

\subsection{Practice of survey, appraisal and inspection}

Survey is the starting point for guidance and recommendations in the repair and refurbishment of buildings. The approach defined for the appraisal must be adapted to the aim and typology to be inspected and should necessarily reflect the final intent pursued, the 
depth and the detail of the inspection, the scale of intervention and the recording tools that are expected to be used.

In the particular case of old buildings, the lack of knowledge on the traditional techniques and materials often leads to inadequate survey techniques which impair a correct diagnosis and, consequently, the efficiency of subsequent retrofitting or strengthening interventions. In this context, ISO 13822 (ISO 13822: 2003) and the International Council on Monuments and Sites (ICOMOS) (ICOMOS/ISCARSAH Committee 2005) establish guidelines and recommendations on the assessment and preservation of built heritage.

Regarding inspection, the need of a thorough understanding and knowledge on the structural typology, building materials and immaterial characteristics is evident. ISO 13822 and ICOMOS also stress the importance of collecting accurate historical information concerning the building construction chronology, even before any appraisal of building defects and damage evaluation.

Among others, a rational approach of the survey stage must be guided by the following principles:

- Each traditional building is unique, presenting different and singular aspects which lead to slightly different survey needs;

- The selection of the means of inspection, appraisal and recording must be adapted to the nature of the building, physical and in-situ limitation of survey actions and available resources;

- The approach to define a survey strategy is clearer when at stake is a decision-making process and what is to be learned. Therefore, questions such as: construction method, modifications over time, nature of materials, mutable use of the buildings, heritage acknowledge importance and long-term conservation actions are the major guidelines;

- The survey is a multidisciplinary task. Thus, the contribution of different professionals (engineers, architects, conservators, historians, archaeologists etc.) with expertise opinion is valuable;

- The use of several sources of information, such as the documentary information, is also very valuable and should be considered.

Lastly, the surveying task usually combines inspection, diagnosis, testing and recording. In this sense, the methodology used in this case study fol- lowed three essential phases: survey framework preparation, fieldwork and data processing. During inspection and diagnosis campaigns, several difficulties and limitations are commonly felt, namely: reluctance of some tenants and home owners to allow the inspection; absence of design projects which would help to understand structural behaviour and to identify cracking phenomena; physical and financial constraints to carry out more precise/conclusive inspections using destructive and non-destructive testing for the diagnosis; unknown history of undated building changes (Vicente et al. 2015).

\subsection{Development of inspection survey checklists}

As part of this work, five survey checklists were developed, improved and used to survey each construction element (roofs, façade walls, timber floors, internal partition walls etc.). Table 1 presents the hierarchical organisation of the inspection and diagnosis checklists.

The initial intent was to create checklists not only to record defects and problems, but also to register construction features and typology. It is worth noting that the checklists should always be complemented with photographic documentation and drawings schemes in two levels of detail: a first level corresponding to an expedite handmade drawing of the building; and a second level corresponding to an accurate representation of the building in a CAD system to support rehabilitation actions.

The data resulting from the inspection work was subsequently processed in a database management system integrated into a GIS application developed to manage, compare and analyse the information. It is worth mentioning that this work represented a singular opportunity, allowing the appraisal, diagnosis and inspection of building stock dating from the $18^{\text {th }}$ to the $20^{\text {th }}$ centuries.

\section{Urban and architectonical characterisation}

\subsection{Notes about the urban expansion of Seixal}

Originating from a small settlement of fishermen, Seixal developed due to the proximity to Lisbon, the capital of Portugal and of the Portuguese Discoveries. Seixal's occupation was connected to its location near the river and its natural resources (see Fig. 1). Buildings before the earthquake of 1755 would have represented a more medieval conception, matching the general idea of some studies on old urban buildings: 
Table 1. Hierarchical organisation of the checklists

\begin{tabular}{|c|l|c|}
\hline \multicolumn{2}{|c|}{ Checklists } \\
\hline $\mathrm{A}$ & General information of the building \\
\hline $\mathrm{B} 1$ & Evaluation of roofs and coverings \\
\hline $\mathrm{B} 2$ & Evaluation of external façade walls \\
\hline $\mathrm{B} 3$ & Evaluation of floor slabs and coverings \\
\hline $\mathrm{B} 4$ & $\begin{array}{l}\text { Evaluation of interior partition walls, } \\
\text { ceilings, window frames }\end{array}$ \\
\hline $\mathrm{C}$ & Evaluation of structural quality and safety \\
\hline $\mathrm{D} 1$ & Evaluation of ventilation, salubrity and natural lighting \\
\hline $\mathrm{D} 2$ & Evaluation of thermal and acoustic conditions \\
\hline $\mathrm{E} 1$ & $\begin{array}{l}\text { Evaluation of the efficiency water systems } \\
\text { and sewerage networks }\end{array}$ \\
\hline $\mathrm{E} 2$ & Evaluation of the electrical network and telephone wires \\
\hline $\mathrm{E} 3$ & Evaluation of fire risk and security \\
of the building
\end{tabular}

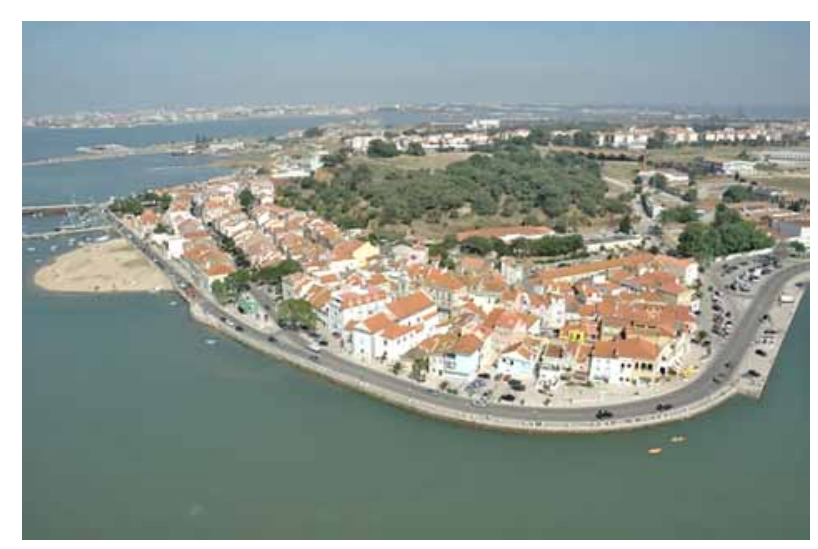

Fig. 1. Aerial view of the old city centre of Seixal

small, narrow and deep plots, housing craftsmen and others, such as carpenters, sailors or caulkers (Carita 1994). The reconstruction of the old urban centre did not follow exactly the plan buildings had previously, as mentioned in Parochial Memories, written in 1756 (Leal, Ferreira 1880). Right after the earthquake, legislation about construction was published recommending technical guidelines that aimed at reducing destruction and victims in similar disasters. Both these facts together imply that the building typologies and construction methods changed after 1755, taking into account security requirements and improving the foundations, structure and resistance of the buildings to fire and seismic events.

As for the history of the urban expansion, according to Santos et al. (2013), the old city centre of Seixal had three key periods. The first one is related to the original core of the city developed around the church square, corresponding to the most labyrinthine area of the urban mesh. The second phase is related to the expansion along the Tagus River, towards east. It is also worth mentioning that the further the houses were from the river, the poorer and smaller they were, being occupied by low social status inhabitants. Later, in the $19^{\text {th }}$ and $20^{\text {th }}$ centuries, better quality constructions were built along the larger street mesh, attesting to the social conditions of their owners. The riverside street was dedicated to the river businesses, and so were its buildings, directly connecting the warehouses, workshops and taverns to the river. This way, all the fluvial activity would not disturb the rest of the city. Finally, in the $20^{\text {th }}$ century started the third phase, in which the urban growth bent inland (Santos 2004). As schematised in Figure 2, the first two phases correspond to the formation of the actual riverfront strip of buildings while the third and last phase corresponds to the formation of the so-called Bairro Novo.

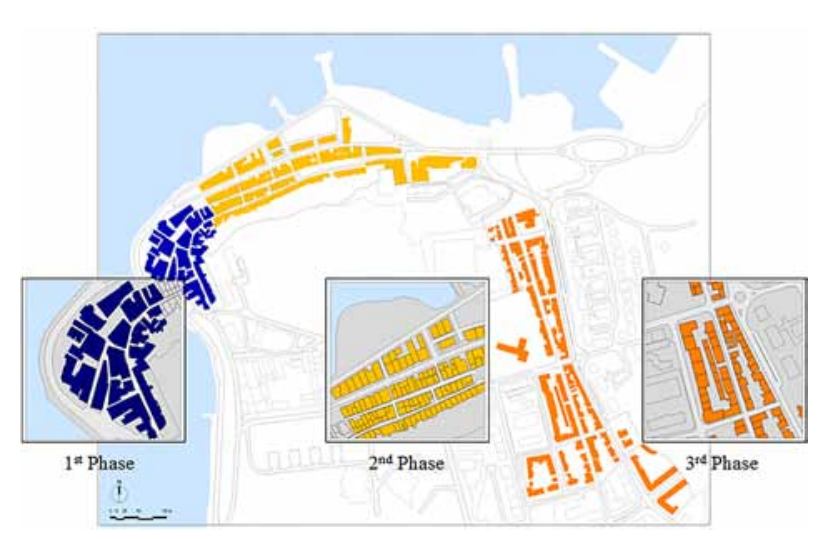

Fig. 2. Evolution of the old city centre of Seixal. expansion periods (adapted from Santos et al. (2013)) 


\subsection{Identification and description of building typologies}

The old city centre of Seixal results from an overlap of different construction periods, translated in a considerable heterogeneity of the buildings. This fact, justified by the constant need to adapt buildings to the requirements of each period, makes the process of definition of different typologies a difficult task. However, there are constructive, formal and organisational aspects that present some repeating patterns.

From the inspection surveys, a typification scheme was proposed considering, namely: the building size, configuration and volume; number of floors; distribution systems and internal space organisation; building materials and the relative construction period (note that given the lack of precise information on the buildings' construction dates, only an approximated dating was possible). From these criteria, four base building typologies, are described in the following sections and summarised in Table 2.

\subsubsection{Narrow front buildings}

The buildings included in this primary typology, the most common ones, correspond to a type used for the reconstruction of Seixal after the Lisbon earthquake in 1755 , and that continued to be built during the following centuries. Narrow front buildings also reflect the social, economic and cultural condition of the inhabitants, mostly families of low social strata who worked on activities related to the fluvial vocation of the area.

In general, narrow front buildings consisted of simple and small sized units organised in a band lay- out, presenting a front façade with around 4 to $7.5 \mathrm{~m}$ width and one flat per floor. Originally, most of these buildings present a two-floor façade wall, which is subdivided into three opening vertical alignments.

Regarding its interior organisation, both the first and the top floor present three compartments. On the first floor, the main entrance leads directly to the living room - the biggest compartment of the dwellings, - which gives access to the kitchen and the bedroom, spaces with similar areas and configurations. The floor plan of the top floor follows the same logic. When compared with the other compartments, which are directed to the rear façade, the living room is a privileged area, with a balcony and a bay window oriented to the street.

The vertical accesses are developed on one of the mid gable walls, leaving the remaining area free for the compartments. The stair position, usually shooting stairs with reduced width, enables both the connection and independence of the floors, giving access to the exterior and to the ground floor. This way, the building can be occupied as a whole or divided into two independent flats.

\subsubsection{Wide front buildings}

Buildings considered of wide front are usually multifamily buildings, with more than $8 \mathrm{~m}$ width and two floors with two flats each, built mainly in the $18^{\text {th }}$ and $19^{\text {th }}$ centuries. The elevations usually show sequences of five openings vertically aligned. On the ground floor there is a central opening that leads to the stairs and two other doors with direct access to the ground floor flat compartments.

Table 2. Synthesis of the old city of Seixal building types (adapted from Santos et al. (2013))

\begin{tabular}{|l|l|l|}
\hline \multicolumn{1}{|c|}{ Description } & $\begin{array}{l}\text { Narrow front buildings } \\
\text { one flat per floor; three vertical window } \\
\text { alignments }\end{array}$ \\
\hline $\begin{array}{l}\text { Wide front buildings } \\
\text { two or more flats per floor; more than three } \\
\text { vertical window alignments }\end{array}$ \\
\hline $\begin{array}{l}\text { Row buildings } \\
\text { long façade wall; thin mid walls; continuous } \\
\text { pitched roof; regular window openings }\end{array}$
\end{tabular}


The interior organisation of the floors shows the living rooms facing the main street, as a hall area, and the kitchens and bedrooms are located on the opposite side. As in the previous model, the reduced number and dimension of the compartments in each flat is related both with the dated living standard and the existence of public basic equipment (sinks, bath etc.), which fulfilled the lifestyle needs at the time but that are now required in each dwelling. The vertical access is located in a central position in order to serve both flats, right and left, and so the high-sloped stairs are supported over lathwork partition walls.

Due to its bigger dimensions, these buildings appear as a result of the availability of the larger dimension of building lots or of the aggregation of smaller adjacent buildings. This fact justifies the birth of a new multi familiar solution, classified into what some authors consider a 'double house' (Carita 1994; Cabrita et al. 1992). Still, these constructions relate to similar social and economic circumstances to the ones presented for the narrow front buildings.

\subsubsection{Row buildings}

From the $2^{\text {nd }}$ half of the $19^{\text {th }}$ century, Seixal started experiencing a period of industrial development caused by the installation of several factories in the area, which attracted people to the city. Therefore, as a result of the need to accommodate the new employees who arrived to work in the booming local industries, the first row buildings were built in Seixal, dating from the late $19^{\text {th }}$ century and the early $20^{\text {th }}$ century. These constructions were based on the repetition of minimum units and the floor plant flexibility, which enabled growth and changeable use of compartments through the simple addition of modules, and represented a huge advantage for the investors who found in this constructive system an economic way to accommodate a large number of employees.

The row buildings are characterised by a long frontage and a continuous roof and trim (eaves or parapet). As shown in Table 2, externally, these buildings present regular and aligned openings. This typology was also adapted to house people of higher socioeconomic conditions and many services that started operating in the city, turning the first austere form of row buildings into a noble construction, presenting more and wider compartments.

\subsubsection{Simple ground floor buildings}

The industrial development of Seixal, and, in particular, the cork industries Mundet \& Sons (1906) and Wicander (1913), led to the growth of the urban mesh in the southern direction, resulting in the foundation of the so called Bairro Novo, wherein a new building typology, with a refreshed image and a new internal organisation, emerged. These new buildings belong to the first half of the $20^{\text {th }}$ century and follow the principles of affordable housing, limiting the construction to the essential, as they were built to house factory workers and their families.

The buildings, ground floor houses, are slightly elevated from the street level, and at the rear side, there are small individual patios and courtyards accessible through the kitchen. The corridor is one of the structural elements of this building type. Unlike the first types where the internal spaces communicate directly with each other, in this typology the corridor is in a central position of the building layout, linking all the compartments (see Table 2).

\section{Structural characterisation of buildings: materials, technology and common defects}

\subsection{Load-bearing stone masonry walls}

When an overall analysis of a certain building is intended it is fundamental to identify both the materials and the construction technology used. According to Appleton (2003), load bearing walls or building walls are those whose geometric and mechanical characteristics are essential to assure the bearing capacity of the building, either when it is under the action of vertical dead loads or when it is affected by random horizontal forces (wind and earthquake).

In the old city centre of Seixal, masonry walls are constituted by irregular fragments of limestone, randomly distributed and linked by lime mortar, sand and earth. Mechanically, this stone is fragile, disaggregating easily. In order to make the wall sturdier, other materials were used to fill in the gaps between the larger stones, namely fragments of quartz, pebbles and pottery shards (bricks and tiles) (see Fig. 3).

Regarding the binding mortars used, they are also clearly influenced by local materials. Ordinary mortars were composed by sand/earth and pebbles - originated from the local sandstone of Santa Ana and the mudslides of the Tagus River - and lime, having also 
been observed clay mortars. The high percentage of earth and sand verified in the masonry walls confers on them a character similar to the mud walls. The low mechanical strength of the limestone, associated with the poor mortars, leads to frequent cases of localised disaggregation. From the structural point of view, this masonry is highly vulnerable to the meteoric action, in particular to rising damp.

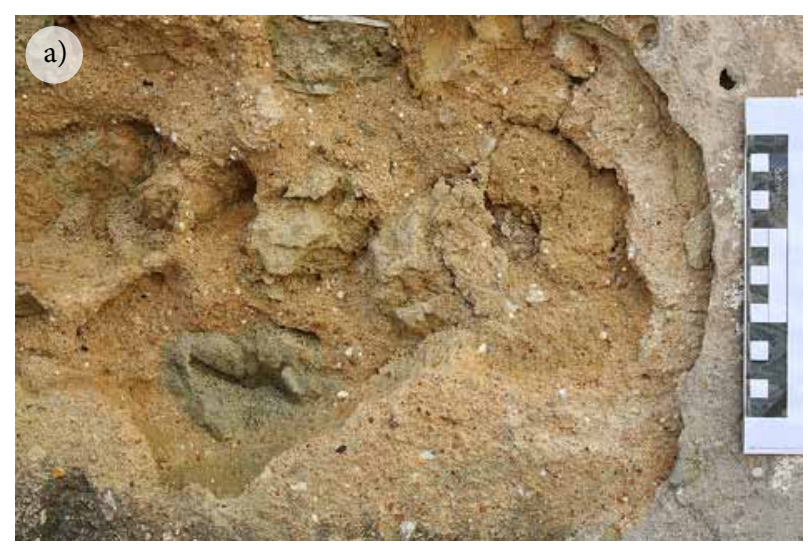

b)
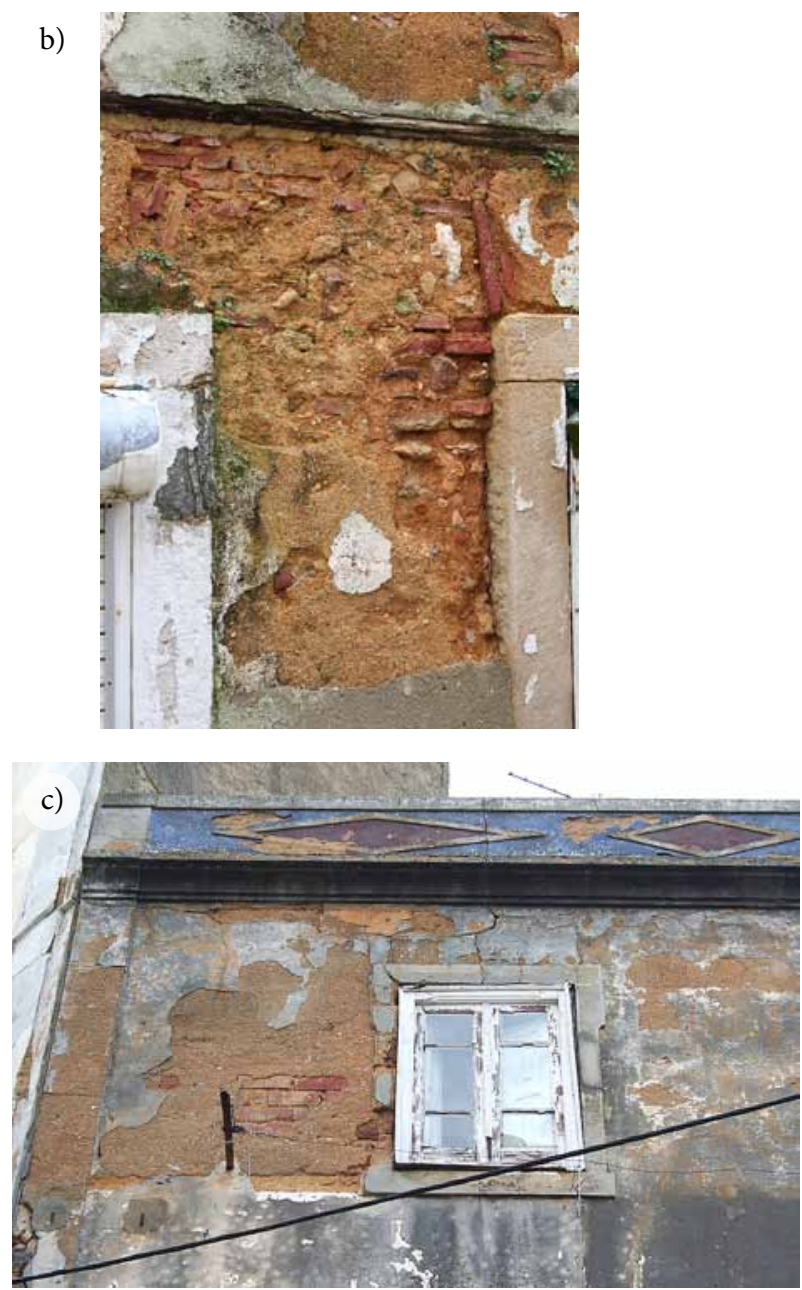

Fig. 3. External aspect of some of the most common masonry types
In addition to the ordinary irregular stone masonry, several cases of 'frontal' walls (wooden structured walls) and simple brick masonry were also identified, the latest mainly used to expand the constructions in height and plan, taking advantage of the lightness of this solution. Figure 3 illustrates masonry types commonly observed in the course of the inspection actions.

With the growth of buildings and the increasing of the medieval lot size, allowing bigger spans, wooden structures have taken on three-dimensionality with the use of wooden elements embedded in the walls. Although these wooden structures do not present high geometric regularity, frontal walls with vertical posts, associated with horizontal and diagonal elements, form the so-called 'St. Andrew Crosses'. The different pieces are notched to allow their fitting and adjustment, being nailed between themselves and the groundsels, which establish the connection with the floors (see Fig. 4).

The mid walls, composed of thinner and lower quality masonry incorporating embedded wooden structures, were often structurally dependent. The link between these walls and the façade walls is crucial to the proper behaviour of such buildings, since this interlocking ensures the box-behaviour, strength and stability of the whole building.

A frequently observed strengthening solution in the old urban core of Seixal buildings consists of the application of iron tie rods to ensure the connection between orthogonal walls and/or the opposite walls, as well as masonry and timber floor structures. These elements were usually applied at the floor and roof levels, being also observed as a measure of post-construction reinforcement. Figure 5 presents some of the most common types of tie rods in the old urban centre of Seixal.

Regarding the wall renders and coatings, it was confirmed the widespread presence of finishing coatings based on plastic paints. Due to its composition containing synthetic polymers, their use on old masonry walls seriously compromises the performance of the coating layers and contributes to accelerate the degradation and detachment of the plaster/render layers that protect the masonry. This type of solution acts as a barrier that prevents the release of water soluble salts which are inside the wall, accelerating the degradation processes.

As for ceramic tiles as a finishing material, they represent a small percentage of buildings. The use of the tile was associated with the idea of durability, since 

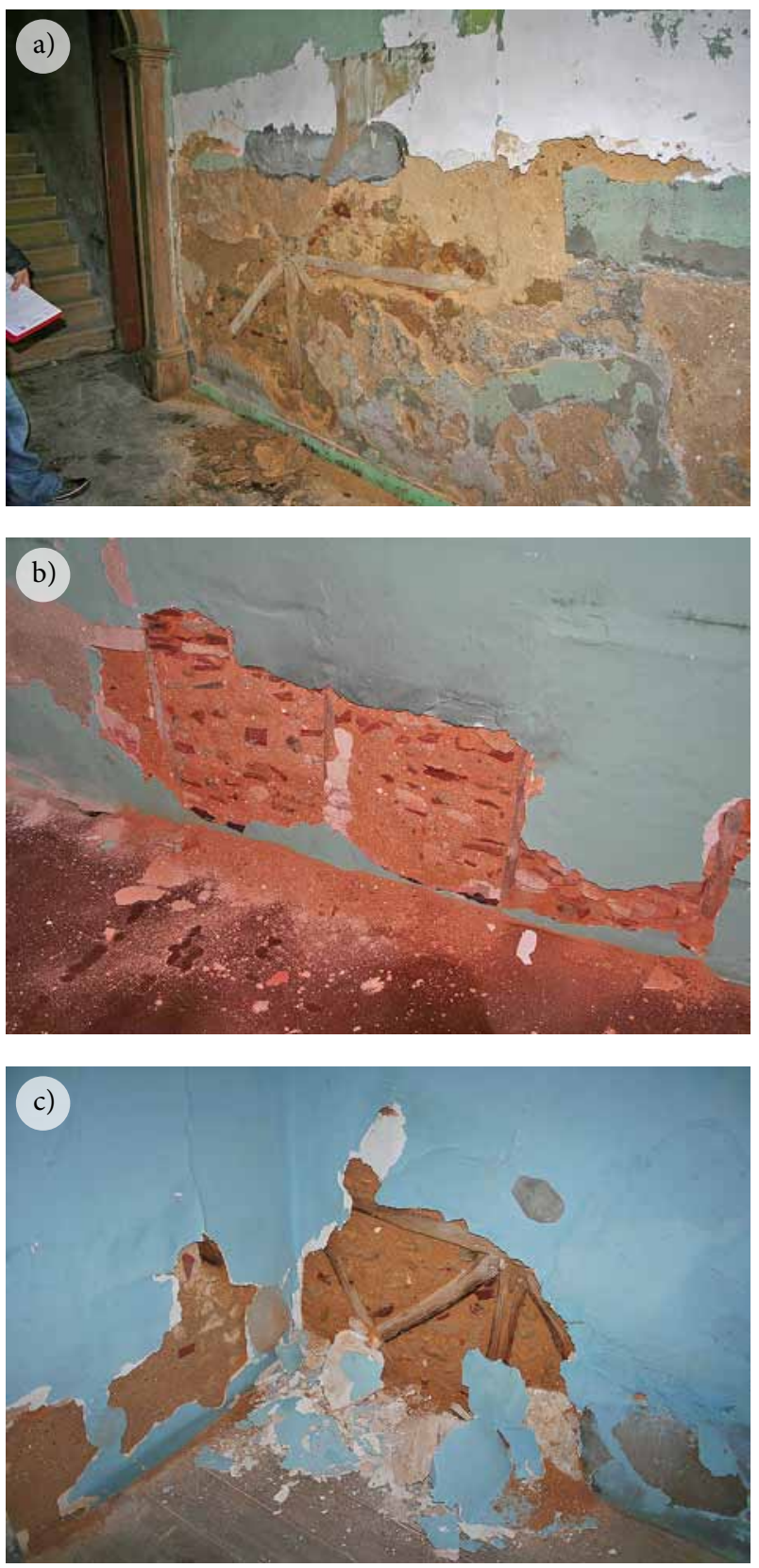

Fig. 4. Masonry walls with embedded wooden structures

this type of solution allowed to maintain the good appearance of the façade during a period of time longer than alternative coating solutions, even in the cases wherein the lack of a conservation practice is evident (see Fig. 6). However, tile detachment is also commonly observed, due to the above exposed phenomenon.

\subsection{Timber floors}

Between the $2^{\text {nd }}$ half of the $18^{\text {th }}$ century and the $1^{\text {st }}$ half of the $20^{\text {th }}$ century, Portuguese construction was guided by the use of wood, motivated by the gaiola three-dimensional timber structures in the Pombalino
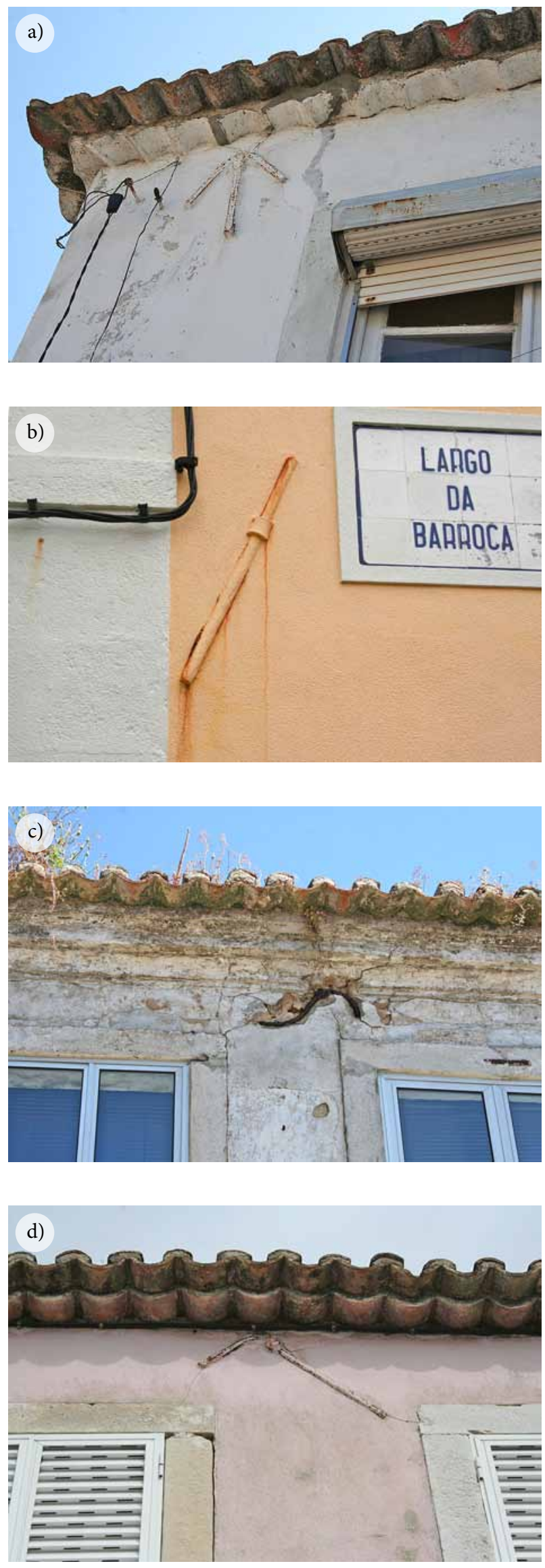

Fig. 5. Examples of tie rods observed in the old centre of Seixal 
buildings. With the generalisation of concrete structures in Portugal, the wooden structures were forgotten, yielding a period of emptiness that, in part, contributed to the lack of maintenance and poor condition of the timber elements in the old buildings (Appleton 2003).

In the old city centre of Seixal, the wood arose for structural use - not only for floor structures but also in the masonry walls, internal partition walls and staircases and foundations (woodpiles) - and also in a nonstructural way - in coverings (floors and lathwork) and in the span linings and frames. Chestnut, oak and pine
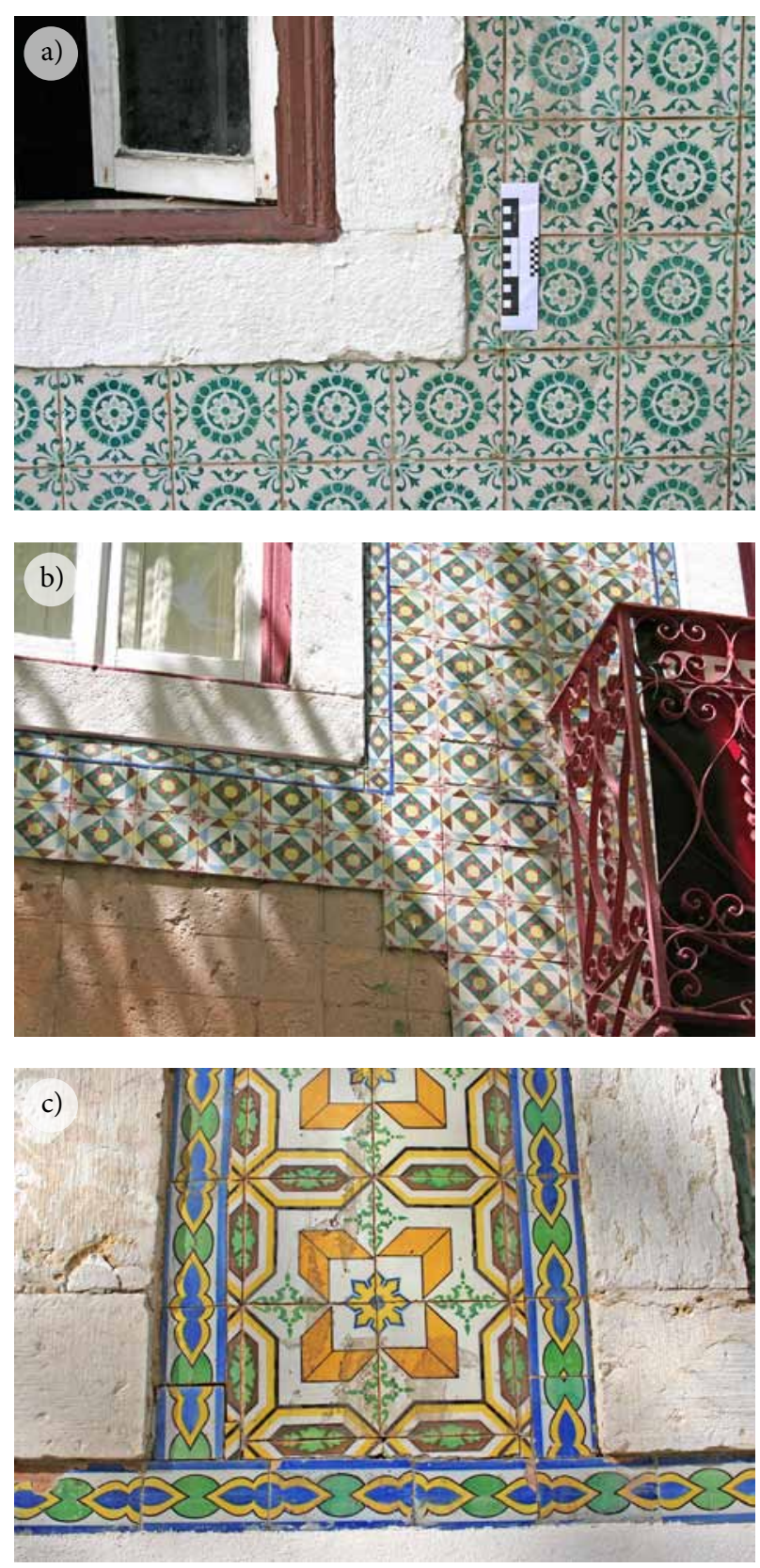

Fig. 6. Tile covering were the most used timber species. Although in less quantity and most likely related to recent interventions, some samples of eucalyptus were also observed.

During the building inspections, different configurations for timber elements were observed, corresponding to different types of cutting, shaping and planning. In the cases where no 'planning' was executed, the timber beams were used as supporting structures, being necessary to foresee and prepare the ends and the connections between the different elements. The shape of the beams depended on the preparation and sawing processes, which influenced its workability on the execution of the assembly elements.

Regarding the inspected floors, they were commonly constituted by parallel wood beams spaced about $40 \mathrm{~cm}$ to $60 \mathrm{~cm}$ (see Fig. 7). However, their cross sections were variable: elements with circular shapes of different diameters were usually associated with ordinary constructions whereas squared elements, with different levels of preparation according to the building characteristics, were associated with more noble and important constructions. Commonly, the dimensions of the rectangular sections ranged between 80 and $140 \mathrm{~mm}$ width and between 140 and $160 \mathrm{~mm}$ or 200 and $220 \mathrm{~mm}$ height, for common (3 to $4 \mathrm{~m}$ ) and larger spans $(>4 \mathrm{~m})$, respectively.

The connection between floors and masonry walls usually consisted on the fitting of the timbering/ framework into openings spaced on the walls with the respective dimensions. Less frequently, the presence of corbels or groundsills, used to distribute the loads avoiding the concentration of shear stresses in the delivery points of the timber beams on the masonry walls, were also observed.

In the old city centre of Seixal, some interesting solutions to strengthen/reinforce the floor structures were verified. It was frequent the use of cast iron columns to overcome large spans, particularly in buildings whose ground floor was intended to be an open space, avoiding partition walls. With the same purpose, there were cases of composite beams, consisting of a timber beam reinforced by two iron rods connected to their ends and linked to an intermediate stanchion, conferring additional in-plane stiffness. Figure 8 presents examples of both solutions described.

Regarding the floor coverings, the buildings inspected mostly present pine wood or Casquinha. The floorboards usually exhibit a flattened finish on both sides, ensuring good connection to the wooden 

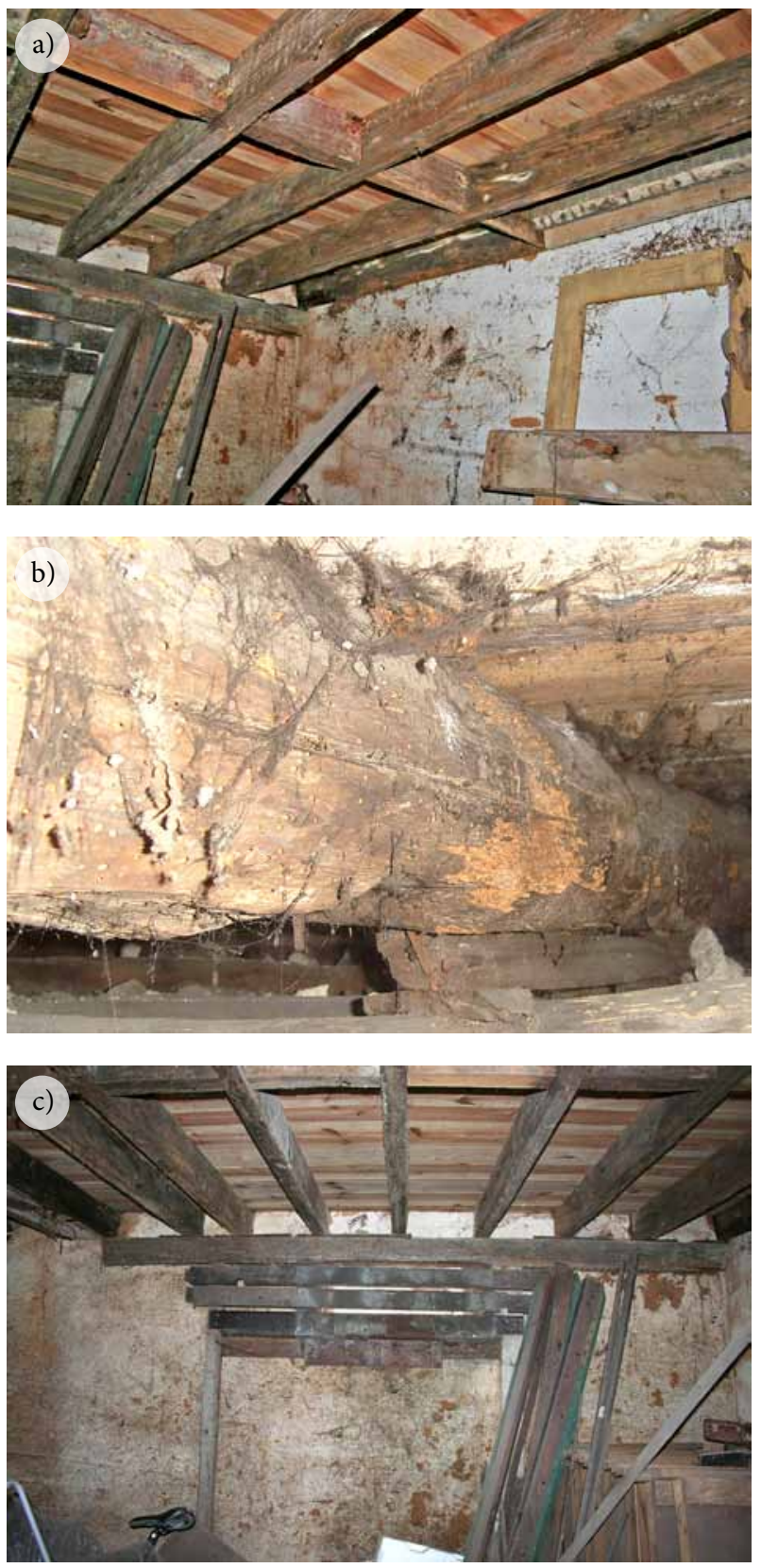

Fig. 7. Types of timber floors

supporting framework underneath. The connection between floorboards was performed in different ways indicated in Table 3 . The boards are usually placed perpendicularly to the timber beams, both elements being traditionally connected through the use of wire nails.

\subsection{Roofs and coverings}

The traditional roofing structure is composed of two distinct elements: the supporting structure (woodwork or frame) and the covering. The first, usually a timber structure in the cases addressed in this paper, can also
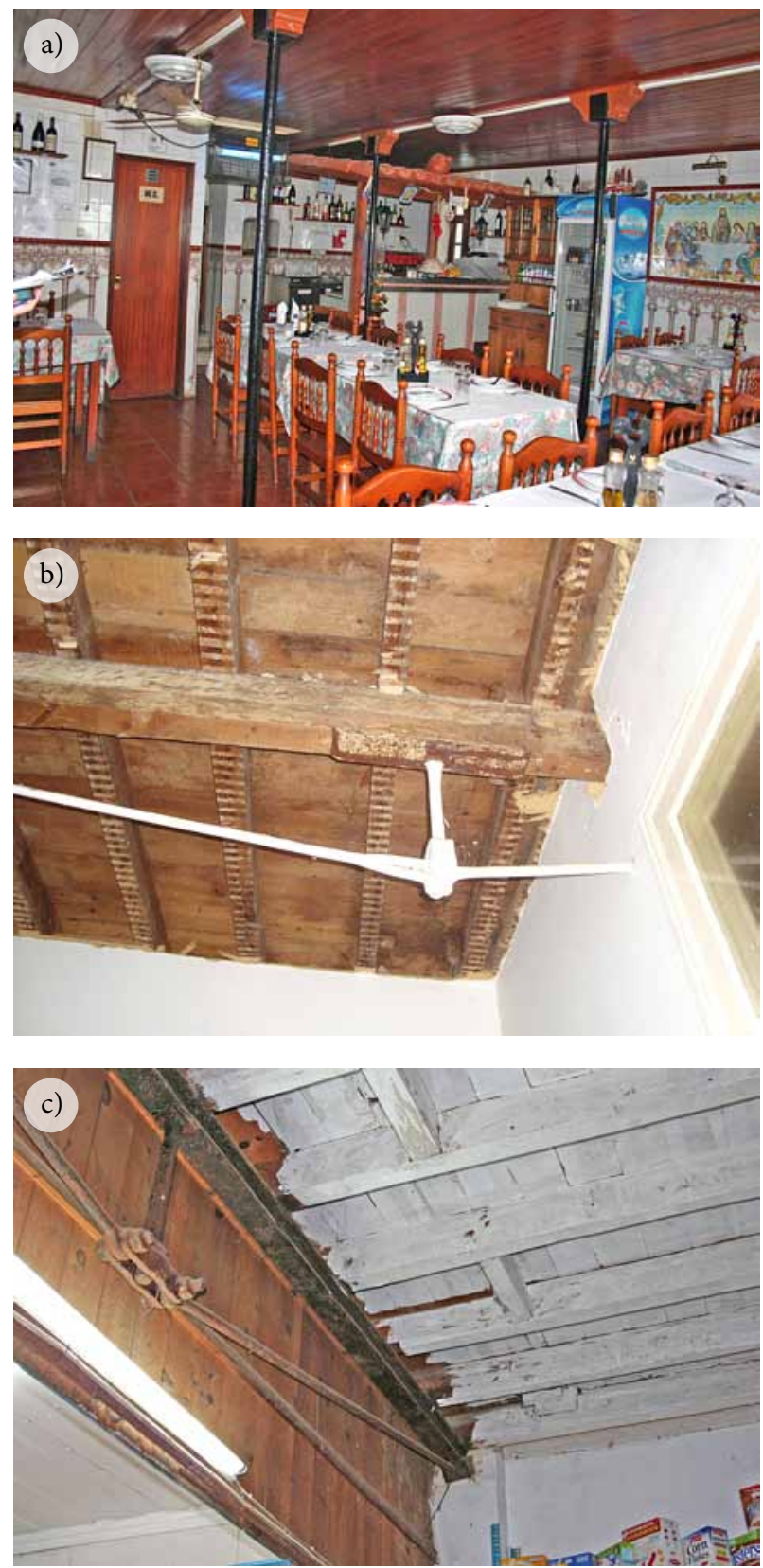

Fig. 8. Original constructive solutions strengthened with metallic elements

be in steel or concrete. Coverings of a different nature were recorded, mostly ceramic tiles and either cases of metal or zinc plates.

The roofs in the old urban centre of Seixal also present a large number of solutions, varying in relation to the geometry, span, slope and covering material (see Figs 9 and 10). The pitched roofs are clearly predominant over the flat roofs, having different shapes and constitutions. Their slopes vary fundamentally with the location of the building into the urban mesh and the use of the roof space - attics, garrets etc. 
Table 3. Different types of floorboard jointing

\begin{tabular}{|l|l|}
\hline \multicolumn{2}{|c|}{ Floorboard types } \\
\hline $\begin{array}{l}\text { Square/Plain floorboard/joint } \\
\text { The floorboards are simply overlapped }\end{array}$ \\
\hline $\begin{array}{l}\text { Bevel/Spayed floorboard/joint } \\
\text { With leaning joints, associated with a less noble construction }\end{array}$ \\
$\begin{array}{l}\text { Portuguese floorboard } \\
\text { Formed by taking two sections with half of the thickness out of two } \\
\text { same side edges }\end{array}$ \\
$\begin{array}{l}\text { Half lap floorboard/Rebated joint } \\
\text { Formed by taking a rectangular section out of one lower edge and one } \\
\text { upper edge of each board, so that they overlap each other when laid }\end{array}$ \\
\hline $\begin{array}{l}\text { Matched/Tongue \& groove floorboard } \\
\text { The connection between floorboards is performed by the match } \\
\text { of tongue and groove elements, producing a better finishing }\end{array}$
\end{tabular}
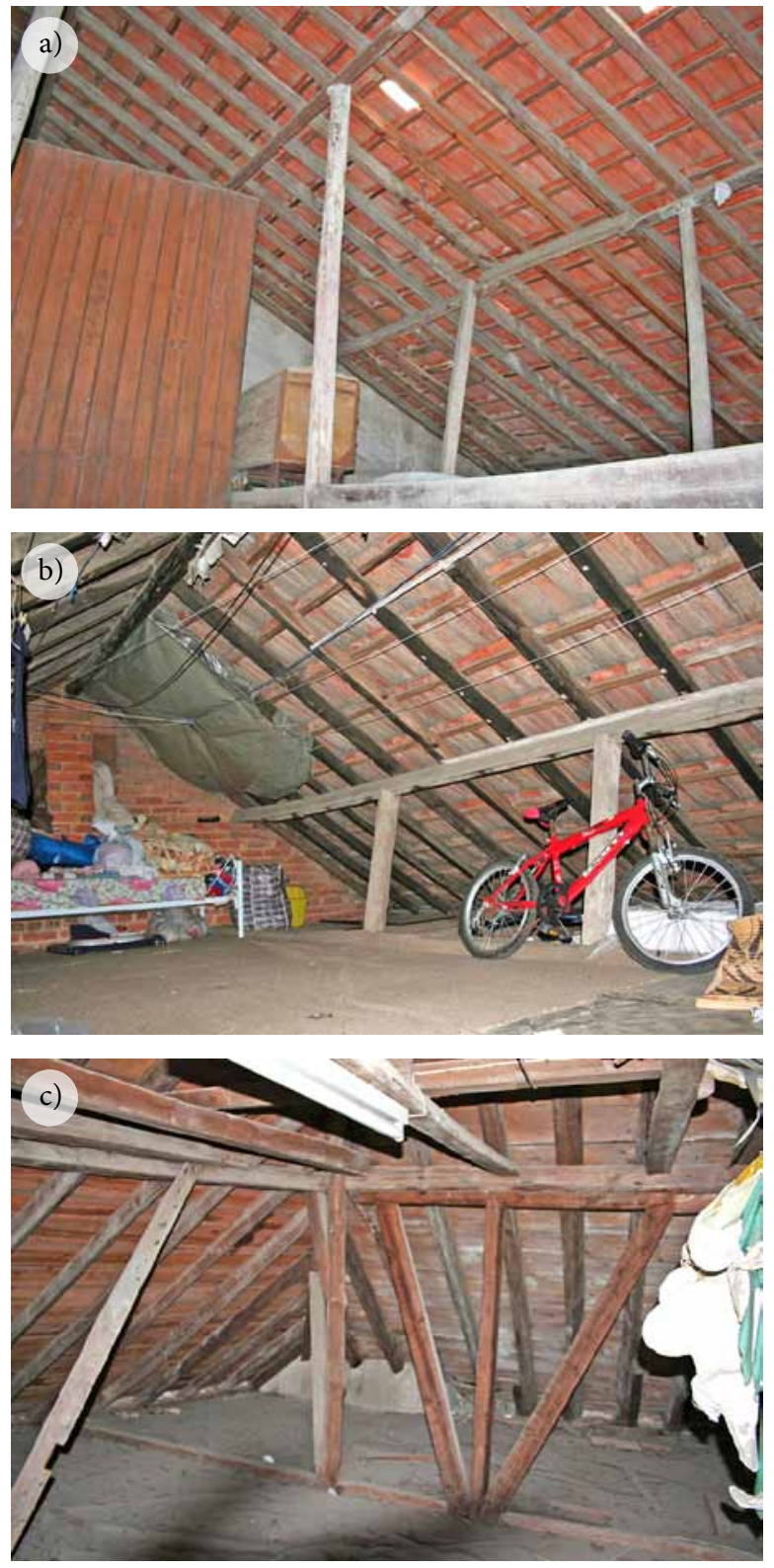

Fig. 9. Examples of different roof structure geometry
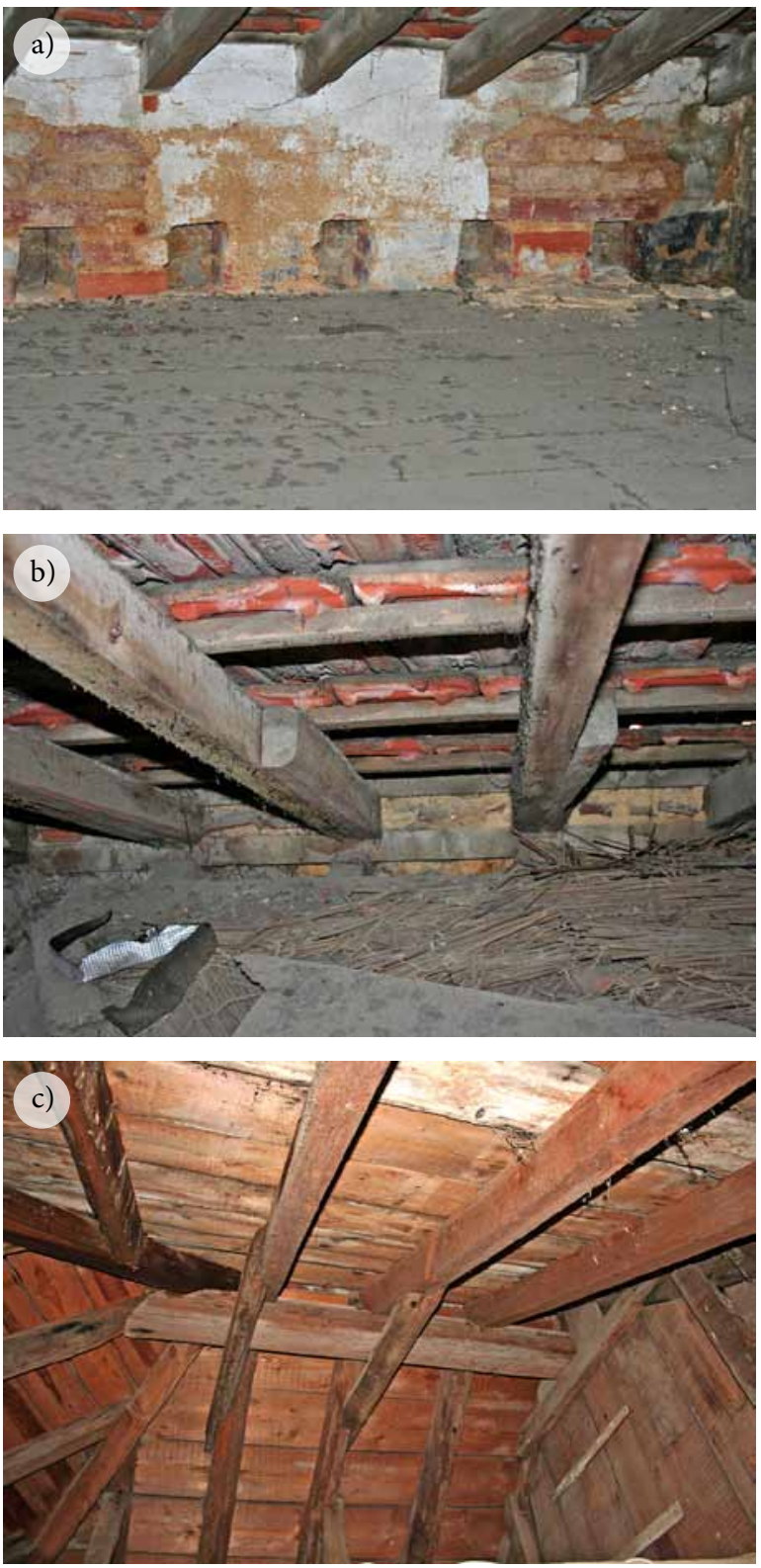

Fig. 10. Geometry and constitution of the supporting structure of the roofs 

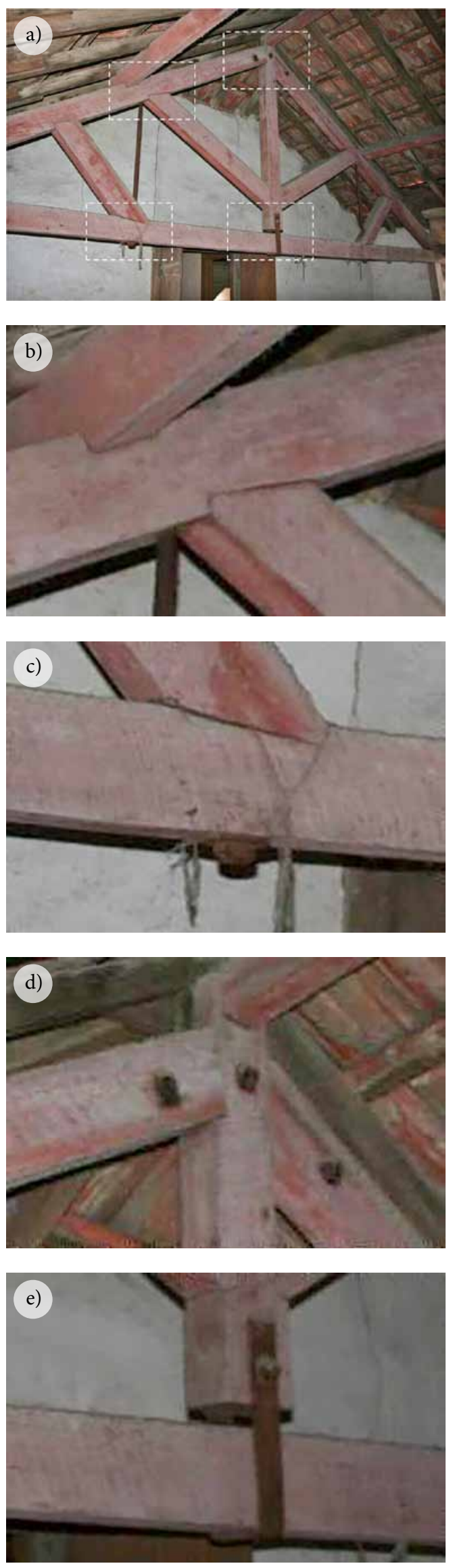

Fig. 11. Types of joints observed in the timber trusses
The fact that many buildings are built in row, having a reduced width, leads mostly to gabled roof solutions. Amongst them, three distinct configurations were recorded (see Fig. 10): a) the structurally simpler solution, which consists of primary timber rafters parallel to the façade, loading on masonry mid walls; b) a structure of a roof ridge beam and rafters discharging on a lintel at the top of the façade walls, as if they were disposed of braces, king-post and line; and c) simple geometry of closed truss. In the case of bigger dimension roofs - larger spans and more slopes the structural solution presents more complexity in terms of the connections and geometry.

The connections between the various elements of the roof structure are mostly nailed. The joints, whose function is to guarantee the transmission of internal forces between the elements to be joined, are carried out by jags, and, in some cases, complemented by the presence of tongue and groove joints. The connections with ironmongeries were observed only in cases of complex trusses and, consequently, for higher spans. Supported by empirical criteria, the size of these connections may vary between widths from 30 to $60 \mathrm{~mm}$, and thicknesses from 5 to $12 \mathrm{~mm}$, determined by the structure's dimension.

Figure 11 a) to e) illustrates different types of joints observed in the timber trusses: $b$ ) tongue and groove joint; c) oblique tongue and groove joints, reinforced with a steel screwed bolt; d) fork joint, reinforced with metallic pins and e) steel brace (U shaped) used to suspend the line through the post.

Finally, regarding the roof coverings, ceramic tiling is the predominant type of covering observed in the old city of Seixal, with Marseille and Lusa representing, respectively, the first and the second most common tiles. In fact, the Portuguese tile has been gradually disappearing. In some cases, it is possible to observe a wide range of materials and solutions, comprising three or four types of coverings for the same roof.

According to the inspections, interventions on the coverings consist essentially of solving watertightness problems by replacing tiles or, more frequently, by applying asphalt screens and underlayment systems. It is worth highlighting that the use of bitumen screens, or other similar solutions, over the traditional roof coverings has serious implications, preventing or conditioning the ventilation of the tiles and the interior attic space, thereby changing the hygrothermic conditions of these spaces. 


\section{Main changes to the original buildings}

Until the beginning of the $20^{\text {th }}$ century, communitarian life and the existence of public equipment for domestic tasks were related to the lack of some infrastructures and the reduced number of compartments in the houses of the old urban centre of Seixal. This conception changed in the course of time, as new hygiene, privacy and comfort standards arose, and so changed the buildings, which were refurbished, expanded or retrofitted, motivated by the adaptability to comfort and hygiene patterns, space requirements or adoption of contemporary construction techniques and materials.

During the fieldwork inspection, several cases of changes were recorded. The most frequent situations comprise the construction of small-attached compartments, usually in the rear façade wall or in the internal courtyards. Furthermore, examples of the creation of new compartments inside the buildings, changing the original floor plans, were also reported.

Most of the inspections revealed that there was also the presence of built-in toilets, connected to the main sewage system. Very often, the space under the stair was used to develop the sanitary facilities, not disturbing the other compartments.

One of the most frequent changes observed is the façade renders and coatings. The replacement of the original wooden window frames and sills by more recent materials such as aluminium is very expressive, and the use of cement based renders and acrylic or plastic paint coats accelerate the degradation.

The building alterations with greatest impact occur at the structural level, namely the opening of large glazing areas/windows in the main façade wall at the ground level and the suppression of load-bearing masonry walls, compromising the shear strength capacity of the building (Ferreira et al. 2014). Another structural alteration that is worth noting is the addition of reinforced concrete floors, stairs and roofs, which has led to the overloading of the masonry walls. In addition to the weight of these new structural elements, connection issues with the existing structure were usually poorly solved. Not always visible, but also worth stressing, are the cases where the steel tie rods are interrupted or disabled, substantially reducing the overall building behaviour to horizontal forces, namely to seismic action.

Therefore, it is quite clear that the human action is negatively linked to constructive problems in old buildings, causing a vast range of defects. However, it is important to note that the principal causes of defects in old buildings are related to the aging process of the materials themselves and the consequent change of the fundamental mechanical properties (elasticity, mechanical strength etc.). Also, in a significant number of cases, the defects arise from natural disasters, with particular emphasis on earthquakes, floods and fires.

\section{Conclusions}

Conservation and rehabilitation actions should be guided by the respect and the safeguarding of heritage, through interventions consistent with the traditional construction techniques and materials. This principle should be applied both to the structural and the non-structural rehabilitation actions in order to avoid accelerated degradation processes originated by the interaction of different construction technologies and materials.

The process of periodic and hierarchical maintenance is also an essential tool to reduce systematic defects. The absence of regular maintenance actions of the roofing structures is often responsible for the premature deterioration of the building as a whole, as well as of other primary elements, such as floors and walls. Moreover, in the rehabilitation process, the absence of project drawings, the reduced knowledge and training of the workers, the adoption of new materials ignoring their mechanical behaviour and the adaption of the building use are all factors that may lead to defects and problems.

In order to preserve the integrity and value of an old city centre, a complete understanding of its features and of its urban environment is absolutely required. In the case of the old city centre of Seixal, two different aspects were taken into account: (i) the urban and architectonical evolution of this building stock, resulting in a typological characterisation; and (ii) a comprehensive constructive characterisation of these buildings, namely through the individual characterisation of their main structural elements.

As dynamic systems, buildings tend to suffer throughout their lifetime several types of interventions, some of which present nowadays a double problem: on the one hand, they are not compatible with the traditional construction techniques and materials; on the other hand, they have distorted the image of the old building stock and are catalysts of accelerated degradation processes. Also important are the more 
intrusive changes with direct impact on the structural safety of the building. i.e., the opening of large spans in the façade wall or the suppression of load-bearing elements at the ground floor level must be highlighted.

As final comment, it is important to emphasise this case study as an example to be followed and echoed for other architecturally valued city centres on three levels: a) inspection methodology based on checklist and recording strategy; b) organisation and management of the old building stock and c) cataloguing building typology and constructive characterisation, as a key action to establish a baseline for any rehabilitation intervention. In fact, it is fundamental and urgent to create this conscientiousness over all the different decision agents involved in such processes to reduce the risk of unqualified interventions. This awareness should also be implicit in specific legislation to safeguard heritage, outlining guidelines, defining building management and establishing criteria for the intervention in old masonry buildings.

\section{Acknowledgements}

The work presented in this paper has been supported and funded by the National Strategic Reference Framework ( $7^{\text {th }}$ Framework European Program) and commissioned by the Seixal City Council.

\section{References}

Appleton, J. 2003. Rehabilitation of old buildings - Pathologies and techniques of intervention. Lisbon: Orion (in Portuguese).
Cabrita, A. M.; Aguiar, J.; Appleton, J. 1992. Rehabilitation manual of buildings in Bairro Alto, Lisbon. Lisbon City Council, LNEC, City Division of Urban Rehabilitation of Historic Centres (in Portuguese).

Carita, H. 1994. Bairro Alto. Typologies and architectonic models. Lisbon City Council (in Portuguese).

Ferreira, T. M., et al. 2013. Seismic vulnerability assessment of historical urban centres: case study of the old city centre in Seixal, Portugal, Bulletin of Earthquake Engineering 11(5): 1753-1773. http://dx.doi.org/10.1007/s10518-013-9447-2

Ferreira, T. M.; Vicente, R.; Varum, H. 2014. Seismic vulnerability assessment of masonry facade walls: development, application and validation of a new scoring method, Structural Engineering and Mechanics 50(4): 541-561.

ICOMOS/ISCARSAH Committee. 2005. Recommendations for the analysis, conservation and structural restoration of architectural heritage. ICOMOS International Committee for Analysis and Restoration of Structures of Architectural Heritage.

ISO 13822: 2003. Basis for design of structures: Assessment of existing structures.

Pinho Leal, A. S.; Ferreira, P. A. 1880. Ancient and Modern Portugal [...]. Vol. 9. Lisbon: Mattos Moreira Editions, 76-81 (in Portuguese).

Santos, C.; Ferreira, T. M.; Vicente, R.; Mendes da Silva, J. A. R. 2013. Building typologies identification to support risk mitigation at the urban scale - Case study of the old city centre of Seixal, Portugal, Journal of Cultural Heritage 14(6): 449463. http://dx.doi.org/10.1016/j.culher.2012.11.001

Santos, J. 2004. The old urban centre of Seixal. Boletim Ecomuseu Informação, 12-15 (in Portuguese).

Vicente, R.; Ferreira, T. M.; Mendes da Silva, J. A. R. 2015. Supporting urban regeneration and building refurbishment. Strategies for building appraisal and inspection of old building stock in city centres, Journal of Cultural Heritage 16(1): 1-14. http://dx.doi.org/10.1016/j.culher.2014.03.004

Tiago Miguel FERREIRA. Tiago Miguel Ferreira is Postdoctoral Researcher of the Aveiro research centre of RIsks and Sustainability in COnstruction (RISCO) at the Civil Engineering Department of the University of Aveiro, Portugal. PhD in Civil Engineering and Post-Graduated in Rehabilitation of Built Heritage, he has participated in several works devoted to the seismic vulnerability assessment of old urban centres, seismic rehabilitation and retrofit of masonry structures and to the characterisation of the outof-plane seismic performance of masonry walls. Author of many international journal and conference papers, his actual research interests are focused on risk management and multi-hazard assessment of urban areas. Member of the International Association of Risk and Crisis Communication (IARCC) and founding member of its Portuguese congener, the Portuguese Association of Risk and Crisis Communication.

Romeu VICENTE. Romeu Vicente is Associate Professor at the Civil Engineering Department of the University of Aveiro, Portugal. Guided and guides students of PhD and master the themes of rehabilitation of the existing building and Risk Assessment. Has coordinated and participated in several European and national research projects in the area of seismic vulnerability assessment of masonry structures and has published a significant number of articles in journals and international and national conferences. Participates in different technical and scientific committees of the CIB International Council for Research and Innovation in Building and Construction. He is a member of the Board of Studies of the Doctoral program InfraRisk: Analysis and Mitigation of Risks in Infrastructures.

Cátia SANTOS. Cátia Santos holds a M.Sc. in Architecture from University of Coimbra, Portugal, where she has developed research over the past few years, namely as a research fellow in a joint project involving University of Aveiro, University of Coimbra and the Seixal City Council, dedicated to the seismic and fire risk assessment of the old urban centre of Seixal. Between 2012 and 2014 she served as collaborating teacher at the Department of Architecture of the University of Coimbra and in 2015 she also participated in the Research Project URBSIS: Assessing Vulnerability and Managing Earthquake Risk at Urban Scale. 
J. A. R. MENDES DA SILVA is Associate Professor at the Civil Engineering and Architecture Department of the University of Coimbra, Portugal. Between 2002 and 2011 he was Pro-Rector of the University of Coimbra, responsible for facilities and infrastructure maintenance, safety and environment protection. He was also member of the coordinator team for the nomination to World Heritage of the University of Coimbra (recognized by UNESCO in 2013). Presently, he is president of the Portuguese advising board of ICOMOS, Member of CIB international Commissions CIB-W023 (Masonry structures) and CIB-W086 (Building pathology) and coordinator of the Master Course in Building Rehabilitation of the University of Coimbra, Portugal. Raimundo Mendes da Silva is author of more than 150 papers in national and international scientific journals and conferences, 10 books and 7 book chapters. 